\title{
First Observations of an Eastern Screech-Owl, Megascops asio, Population in an Apple-Producing Region of Southern Quebec
}

\author{
Ngaio L. Richards ${ }^{1}$, Pierre Mineau ${ }^{2}$, David M. Bird ${ }^{3}$, Pierre Wery ${ }^{4}$, JacQues LarivéE ${ }^{5}$, and \\ JASON DUFFE 6
}

${ }^{1}$ Anglia Ruskin University, East Road, Cambridge CB1 1PT United Kingdom; e-mail: n.richards@anglia.ac.uk

${ }^{2}$ Canadian Wildlife Service / National Wildlife Research Centre, Environment Canada, 2 Raven Road, Carleton University, Ottawa, Ontario K1A 0H3 Canada

${ }^{3}$ Avian Science and Conservation Centre, Department of Natural Resource Science, McGill University, Macdonald Campus, 21, 111 Lakeshore Road, Ste-Anne-de-Bellevue, Québec H9X 3V9 Canada

${ }^{4}$ Parc national du Mont-Saint-Bruno, 330 rang des 25 Est, Saint-Bruno-de-Montarville, Québec J3V 4P6 Canada

${ }^{5}$ Étude des populations d'oiseaux du Québec, 194 Ouellet Street, Rimouski, Québec G5L 4R5 Canada

${ }^{6}$ Cégep de Rimouski, 60 Évêché ouest, Rimouski, Québec G5L 4H6 Canada

Richards, Ngaio L., Pierre Mineau, David M. Bird, Pierre Wery, Jacques Larivée, and Jason Duffe. 2006. First observations of an Eastern Screech-Owl, Megascops asio, population in an apple-producing region of southern Quebec. Canadian Field-Naturalist 120(3): 289-297.

Baseline information was collected on a local Eastern Screech-Owl population found in the apple-producing region of Saint-Hilaire and Rougemont, Quebec, as part of a larger study on pesticide exposure conducted between 2000 and 2003. Screech-Owls visited or occupied 41 of 89 nest boxes installed in 12 orchards and 2 control locations. The mean height of occupied nest boxes was $3.83 \mathrm{~m}(2.00-5.80 \mathrm{~m})$. Squirrels, Sciurus and Tamiasciurius sp., and chipmunks, Tamias striatus, Northern Flickers, Colaptes auratus, and wasps were the owls' primary competitors for the boxes. Intact Screech-Owl pellets retrieved from nest boxes $(n=82)$ had a mean length and width of 3.57 and $1.44 \mathrm{~cm}$, respectively, and weighed a mean of $1.77 \mathrm{~g}$. Screech-Owls in the study area consumed a variety of small mammal, avian, insect and aquatic prey. Of these, Meadow Voles, Microtus pennsylvanicus, were the predominant prey item identified in pellets, and Mourning Doves, Zenaida macroura, were the primary avian prey found in nest boxes. In Canada, the owl's trend status remains largely unknown. The species is currently listed as "Not at Risk", based on an assessment conducted for COSEWIC in 1986. Given that a limited amount of information exists on the natural history and ecology of the species in Quebec, we also generated a map of the owl's distribution in the province, using data from ornithological databases and rehabilitation facilities. Potential risks to the species within the province, particularly pesticide exposure and habitat loss, are briefly addressed and follow-up studies are discussed.

Key Words: Eastern Screech-Owl, Megascops asio, natural history, ecology, apple orchard, Quebec, range, distribution, census, pellet analysis, prey inventory, nest box, wing chord, population management, pesticide exposure, habitat loss, development, conservation.

The Eastern Screech-Owl, Megascops asio, has been extensively studied in the United States (i.e., VanCamp and Henny 1975; Gehlbach 1994a). However, it has received considerably less attention north of the border, where it occupies a much smaller area. Within Quebec, the Screech-Owl's range is vaguely delineated and general knowledge about the species is limited. As part of a study assessing the exposure of the ScreechOwl to pesticides currently and previously used in apple orchards of southern Quebec (see Richards et al. 2004, 2005), we collected baseline information on the species. Here, we present observations on a population of Eastern Screech-Owls (Figures 1, 2, 3 that resides in one of the primary apple-producing regions of Quebec.

\section{Methods}

Mapping the range of the Eastern Screech-Owl in Quebec

We obtained case files from the Clinique des oiseaux de proie (COP), based in Saint-Hyacinthe, and the Center for the Rehabilitation of Injured Birds of the Mon- térégie (CRIB), based in Otterburn Park, which administer care to the majority of injured or orphaned owls in the province. The locations from which adult and juvenile Screech-Owls were admitted were tabulated and mapped. These data harbour certain biases and so were used only to illustrate the overall, rather than density, distribution of the species within Quebec. For example, the number of owls admitted from an area is positively correlated with its proximity to the nearest rehabilitation facility (Richards et al., unpublished data). Visibility and predisposition to capture can artificially inflate admission numbers; in this case facilities tend to receive an influx of orphaned Screech-Owl babies and fledglings in the late spring and summer, largely from suburban settings, where they are highly conspicuous (Richards et al., unpublished data). Thus, each admission location was given one data point, and multiple admissions from any given area were not considered an indication of a large Screech-Owl population or that it was especially suitable for the species. 
We also obtained Screech-Owl locations from the Études des populations d'oiseaux du Québec (ÉPOQ) database, which is managed and continually updated by members of ornithological clubs and societies belonging to the Association québécoise des groupes d'ornithologues (AGQO). Finally, we contacted personnel from the Ontario Breeding Bird Atlas project (OBBA) and from the New Brunswick division of Bird Studies Canada to ensure that our map represented the species' range at the eastern and western borders of Quebec as precisely as possible.

\section{Site selection and censusing}

All fieldwork was carried out in orchards of Rougemont and Saint-Hilaire $\left(45^{\prime} 28^{\prime \prime} 73^{\circ} \mathrm{W}\right.$ to $\left.45^{\prime} 32^{\prime \prime} 73^{\circ} \mathrm{N}\right)$, two adjacent apple-producing regions of southern Quebec. The study region was first surveyed in the summer of 2000 for areas containing habitat requirements for Screech-Owls; i.e., mature and mixed forest with old cavity-ridden trees and conifers for shelter, as well as running water. Potential orchards and control sites were then censused between November and March 2000 and 2002. By November, most first-year individuals should have dispersed from their natal habitat and established a territory. Thus, owls that respond are likely to be established, rather than transient, individuals. This provides a "true sense" of occupancy. We have found, based on our experience censusing ScreechOwls in southern Quebec, that this timeframe also corresponds to the period when individuals are reasonably responsive to broadcast calls.

We walked or snowshoed between the edge of the orchard and the adjacent forest, broadcasting a combination of "bounce" (territorial) and "whinny" (defensive) calls into the forest from a small, hand-held tape player. Between 3 and 7 minutes of silence followed, and then the calls were repeated. If a response was not obtained, we then proceeded around the perimeter and repeated the process roughly 10 minutes later. When a response was obtained, the presence of an individual was visually confirmed with a headlamp or flashlight and its colour phase was noted. Two individuals observed in the immediate vicinity of one another (i.e., perched in the same tree) were considered a pair. We also noted responses from Barred Owls, Strix varia, or Great Horned Owls, Bubo virginianus. The presence of these potential predators in an area may cause Screech-Owls to suppress vocalizations (Fuller and Mosher 1981), restrict the size of their territory, or deter them from establishing themselves altogether (Gehlbach 1994a).

The locations were then re-censused every winter to verify whether or not they were still occupied. The 12 orchard and 2 control sites where Screech-Owls were observed in the winter were censused again in June and July of 2001 and 2002. Given that ScreechOwls are not always particularly cooperative even under optimal conditions, locations were repeatedly censused (at least twice) if a response was not obtained during the first censusing effort. We did not census when wind speed exceeded $15 \mathrm{~km} / \mathrm{h}$, or during rain or snow, to ensure that censusing was carried out under the best possible conditions.

\section{Nest box installation and inspection}

Between 2000 and 2002, 89 nest boxes were installed in the forests where Screech-Owls responded during our initial censusing efforts. All orchards were assigned a letter code to maintain orchard-owner confidentiality. Boxes were constructed of pine, Pinus sp., or Eastern Hemlock, Tsuga canadensis, with dimensions for American Kestrel, Falco sparverius, as per Henderson (1992). Material does not appear to influence nest box selection by Screech-Owls (Gehlbach 1994b). One caveat is that boxes made of hemlock must be stored under conditions of relatively uniform heat or they will crack and warp. Pine boxes are heavier and more challenging to transport but much more resistant to temperature fluctuations, both inside during storage and in the field.

Between 1.0 and 2.0 inches of dust-free wood chips were placed in the bottom of each box. The distances from the base of the box to the ground and from the box to the nearest orchard edge were recorded. Nest box covers were secured on each side with springloaded latches to facilitate inspections while minimizing entry by mammalian predators, particularly Raccoons, Procyon lotor. Though most locations were fairly remote, boxes installed in areas regularly accessed by the public were painted with a brown, nontoxic paint, and placed a greater distance from the ground to reduce visibility and the possibility of disturbance or vandalism (as described in Gehlbach 1994b).

Boxes were initially inspected for pellets and prey remains 3 to 4 times per year: in the spring, in mid to late summer, in the late autumn and in the early winter, depending on ease of accessibility to each site especially during periods of heavy snowfall. However, we soon stopped inspecting in the spring and summer because of the disturbance posed to other species occupying the boxes; unfortunately, we unwittingly caused nuthatch, Sitta sp., and European Starling, Sturnus vulgaris, parents to abandon their nests. From an ethical and logistical perspective, the late autumn and early winter were deemed the best times to inspect nest boxes. Thus, between 2003 and 2004, boxes were inspected once or twice per year in the late autumn and/or early winter. When prey items were found, boxes were emptied and replenished with wood chips to prevent duplication of results on subsequent visits. Recovered wood chips were carefully sifted for pellets or prey items.

\section{Pellets, prey remains and prey inventory}

Pellets were air-dried prior to dissection for prey identification. Length, width and weight of intact pellets were recorded. Small mammal species were identified by lower mandible (Cahn and Kemp 1930; Rac- 
zynski and Ruprecht 1974), using a reference collection of known skulls and mandibles. Vole species were further distinguished as Clethrionomys or Microtus sp. using Maisonneuve et al. (1997). Avian prey were identified to species from feather remains with the help of two local wildlife rehabilitators, and referring to Elbroch and Marks (2001). An inventory was then drawn up for each of the locations where prey items were found.

\section{Screech-Owl captures}

Screech-Owls were initially captured between June and August of 2001 and 2002 as part of an unsuccessful attempt to radio-track them and evaluate their use of orchards in relation to pesticide applications. We set up a mist net and a bal-chatri trap baited with a white mouse within orchards but near adjacent forest (as per permits no. 2001-05-07-103-16-SF and 2002-06-10$120-16-\mathrm{SF})$. We then broadcast defensive and territorial calls into the forest to attract owls. Capture attempts were initiated just prior to or soon after dusk.

All captured adults and young were processed onsite. First, they were placed headfirst into a clean Pringles ${ }^{\circledR}$ chips canister and weighed with a $300 \mathrm{~g}$ spring-loaded Pesola scale. After the owl was removed from the canister, the keel region was gently palpated and a keel index was assigned on a scale of 0 to 5 , with 1 being "emaciated", 3 being of "medium" weight, and 5 being "obese". The wing chord was also measured. Owls were aged as adults based on the presence of blood feathers and on other evidence of moulting. It was not possible to sex individuals. All owls were banded and released.

\section{Results}

\section{Range map}

One hundred and sixty-nine locations were plotted: 20 from the COP (records spanning 1998 to 2001), 17 from the CRIB (records spanning 1988 to 2003), 7 from the OBBA (2001 to 2004 data) and 125 from the EPOQ database (1940 to 2004). According to the personnel at the New Brunswick division of Bird Studies Canada, the species is incidental at best in the Maritime provinces, and they were unable to provide us with definitive sightings.

\section{Censusing}

Between the winters of 2000 and 2002, we censused 27 orchards and 3 potential control sites. We received a response from Screech-Owls in 12 orchards and 2 control sites, one a wooded area near a trailer campground and the other in the research sector of the MontSaint-Hilaire Biosphere Reserve. Four pairs and 7 individuals were observed during censusing and all were grey-phased.

Great Horned Owls or Barred Owls were heard or seen in the vicinity of 6 of the 14 locations occupied by Screech-Owls and 6 of the 16 remaining locations. It is likely that some or all of the locations where we did not obtain a response are frequented by one or both

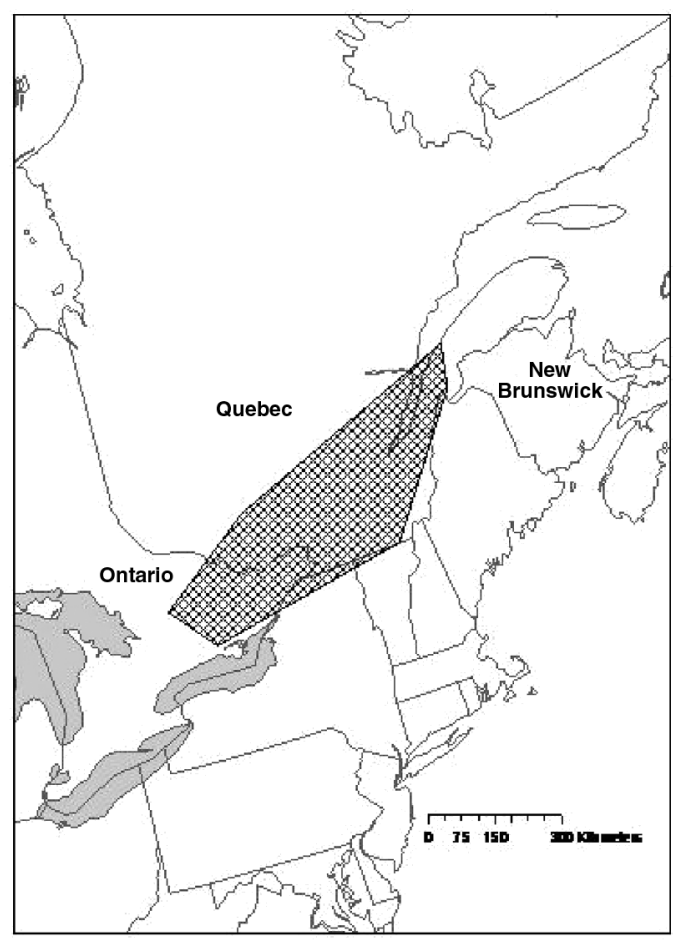

FIGURE 1. Distribution of the Eastern Screech-Owl (Megascops asio) in Quebec.

species; the habitat observed is suitable and they are all either quite close to the Mont-Saint-Hilaire Biosphere Reserve or to Mont Rougemont, both of which have Great Horned Owl and Barred Owl populations (C. Cormier, personal communication 2003).

\section{Nest box occupation}

A nest box was considered occupied if pellets, prey remains or an owl were observed in it during inspections (Table 1). To determine whether height of nest box or distance from box to nearest habitat/forest edge influenced its selection or use, we first considered the height and distance of those boxes occupied at least once by a Screech-Owl. Then, we further refined our analysis to nest boxes for which we had evidence of multiple uses, defined as three visits or more (Table 2): either evidence of occupancy on at least three separate nest box inspections or discovery of at least three pellets or prey remains, given that Screech-Owls generally regurgitate one pellet per resting period.

We measured the distance from the tree on which nest boxes were installed to the nearest "true' edge", an important distinction as a network of paths crisscrossed most of the forests in which boxes were installed. True edge was defined as an expanse of open area immediately adjacent to, rather than contained within, the forest itself, such as a field or an orchard. Box distance ranged from 0 to $68.0 \mathrm{~m}$ from edge. 
TABLE 1. General nest box occupancy of Eastern ScreechOwls, by location, in Saint-Hilaire and Rougemont, Quebec areas $(2000-2004)$.

\begin{tabular}{lcc}
\hline \hline Location & $\begin{array}{c}\text { Number of } \\
\text { boxes installed }\end{array}$ & $\begin{array}{c}\text { Percent } \\
\text { occupation }\end{array}$ \\
\hline Campground & 9 & 89 \\
Biosphere Reserve & 6 & 100 \\
A/A1 & 7 & 14 \\
B & 10 & 30 \\
K & & \\
C & 8 & 25 \\
D/F & 5 & 20 \\
G & 10 & 100 \\
I & 7 & 14 \\
M & 11 & 0 \\
N/N1 & 7 & 29 \\
Total & 9 & 78 \\
\hline \hline
\end{tabular}

A variety of other species occupied the nest boxes (see Table 3). To determine the overall frequency of nest box use, we evaluated the total number of times boxes were occupied by Screech-Owls at each site over the course of the study relative to other species. Table 4 shows occupation by the most commonly observed species in relation to that by Screech-Owls.

\section{Pellets and prey remains}

Nest boxes were installed at the 12 orchards and 2 control locations where Screech-Owls responded to censusing. However, in some of these locations, there was little or no evidence (i.e., pellets or prey remains) that Screech-Owls ever occupied these boxes. Only one pellet was found at Orchards A/A1, C and M, so these were excluded from the prey inventory analysis (Table 5). Intact pellets were retrieved from 8 of the orchards, including $\mathrm{C}$ and $\mathrm{M}$, which were included in the analysis of pellet dimensions.
TABLE 2. Mean height from ground of nest boxes $(n=41)$ occupied by Eastern Screech-Owls in Saint-Hilaire and Rougemont areas, Quebec (2000 - 2004).

\begin{tabular}{lcc}
\hline \hline & $\begin{array}{c}\text { Height from } \\
\text { ground }(\mathrm{m})\end{array}$ & Range \\
\hline Unoccupied boxes $(n=48)$ & 4.22 & $2.40-6.82$ \\
Occupied boxes $(n=41)$ & 3.83 & $2.00-5.80$ \\
"High-use" nest boxes $(n=33)$ & 3.67 & $2.00-4.72$ \\
\hline \hline
\end{tabular}

\section{Screech-Owl captures}

Despite repeated censusing, a response was never obtained in Orchards G or M. These locations were therefore excluded from capture attempts. We did obtain a response in Orchard C, but the owl never deigned to approach our traps.

Nine individuals were captured in the summers of 2001 and 2002. On occasion, Screech-Owls began to respond to broadcast calls while some daylight remained. However, owls were always captured under cover of darkness, between 21:15 to 03:10. Though we were not always able to capture all the individuals observed, we did record their presence (see Table 6). Of the nine captured individuals and six observed, but not captured, only one was red-phased; the rest were grey.

\section{Discussion}

\section{Eastern Screech-Owl range in Quebec}

The Eastern Screech-Owl's northernmost North American range coincides with the southern tip of Quebec (Gauthier and Aubry 1996). To the west of Quebec, the species is commonly reported along the southern edge of Ontario in the Carolinian zone along Lake Erie and Ontario. More local and uncommon populations extend up another 100 to 200 kilometres north. In eastern Ontario, there appears to have been

TABLE 3. Nest box occupancy by other species.

\begin{tabular}{lll}
\hline \hline & & \\
Mammal occupant & Avian occupants & Other \\
\hline $\begin{array}{l}\text { Eastern chipmunk } \\
\text { (Tamius striatus) }\end{array}$ & Great Crested Flycatcher & Hymenoptera: \\
Southern Flying squirrel & (Myiarchus crinitus) & Eees*, wasps \\
(Glaucomys volans) & Downy Woodpecker & Earwigs \\
Grey squirrel & (Picoides pubescens) & Unknown snake** \\
(Sciurus carolinensis) & European Starling & Arachnid: \\
Jumping Mouse & (Sturnus vulgaris) & Spiders \\
Zapodidae & Hairy Woodpecker & Coleoptera: \\
Red squirrel & (Picoides villosus) & Unknown beetles \\
(Tamiasciurus hudsonicus) & Northern Flicker & (Colaptes auratus) \\
\end{tabular}

*could also have been cached prey item

**snakeskin found, could also have been part of nesting material 
an overall expansion of the range in the last 20 years (M. Gahbauer, personal communication, 2004). To the east of Quebec, the range may extend into the extreme southwestern part of New Brunswick (Gauthier and Aubry 1996); however, there are no confirmed breeding records for the species there. If Screech-Owls do in fact breed in New Brunswick, it is likely to be in very low numbers (B. Whittam, personal communication, 2004). Screech-Owls have also been observed in Nova Scotia and in Prince Edward Island, but their presence there is thought to be incidental (ibid). Elsewhere in Canada, the range is defined as extending from southwestern Saskatchewan to southern Manitoba (Panak 1988*). All of the above suggests that an important proportion of the species' range in Canada occurs in Quebec and in Ontario.

\section{Censusing}

For our purpose, which was to confirm the presence of resident Screech-Owls at a given location, we found the optimum census period to be between November and February. There are several logistical advantages to censusing towards the beginning of this period. During the early winter months, pairs jointly defend their territory and are very responsive to broadcast calls. As a result, there is a greater likelihood of obtaining a response from both the male and the female, which eliminates the need for speculation as to whether or not a location is occupied by a pair. Later on, heavy snowfall can lengthen the time required to census each location considerably, and render some virtually inaccessible.

Censusing can have adverse effects. In late February and early March, females select a suitable nesting location, then remain in or near their cavity. Broadcast calls may elicit a response from territorial males, but

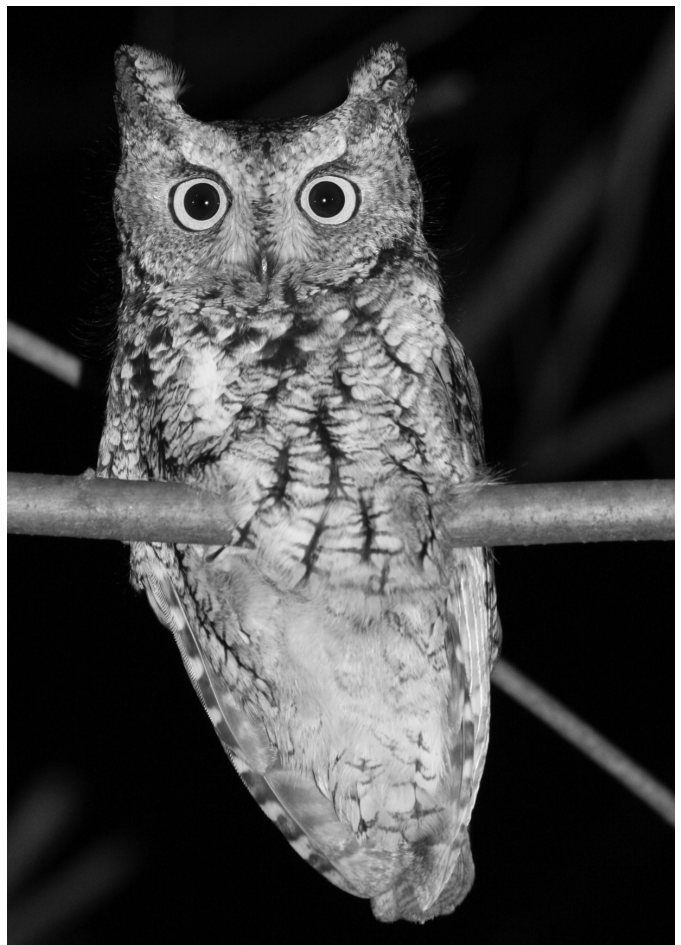

FIGURE 2: A grey-phase Screech-Owl discovered during a mid-winter census at the Réserve écologique MarcelRaymond, Henryville, Quebec, near the Richelieu River. Photographed by Léopold Gaudreau, Assistant Deputy Minister, Sustainable Development Branch, Ministère du Développement durable, de l'Environnement et des Parcs. 9 December 2006.

TABLE 4. Frequency of nest box occupation in orchards and control sites of Saint-Hilaire and Rougemont areas, Quebec $(2000-2004)$

\begin{tabular}{|c|c|c|c|c|c|c|c|}
\hline Location & $\begin{array}{c}\text { Number of } \\
\text { boxes inspected } * *\end{array}$ & ESOW & $\begin{array}{l}\mathrm{CH} / \\
\mathrm{SQ}\end{array}$ & NOFL & WASP & OTHER & $\mathrm{NO}$ \\
\hline Biosphere Reserve & 38 & 26 & 2 & 1 & 0 & 0 & 9 \\
\hline Campground & 116 & 48 & 26 & 3 & 5 & 5 & 29 \\
\hline $\mathrm{A} / \mathrm{A} 1 *$ & 60 & 8 & 4 & 5 & 1 & 7 & 35 \\
\hline $\mathrm{B} / \mathrm{K}^{*}$ & 173 & 16 & 39 & 9 & 7 & 9 & 93 \\
\hline $\mathrm{C}$ & 47 & 4 & 10 & 6 & 1 & 1 & 25 \\
\hline $\mathrm{D} / \mathrm{F}^{*}$ & 103 & 20 & 33 & 2 & 3 & 4 & 41 \\
\hline $\mathrm{G}$ & 51 & 5 & 13 & 2 & 1 & 5 & 25 \\
\hline I & 67 & 2 & 29 & 0 & 1 & 9 & 26 \\
\hline M & 39 & 4 & 22 & 0 & 2 & 0 & 11 \\
\hline $\mathrm{N} / \mathrm{N} 1 *$ & 59 & 13 & 24 & 1 & 3 & 7 & 11 \\
\hline Total & 753 & 146 & 202 & 29 & 24 & 47 & 305 \\
\hline
\end{tabular}

* Orchards are side by side or adjacent

**Indicates number of boxes inspected at location over duration of the study

ESOW: number of boxes occupied by Screech-Owl

$\mathrm{CH} / \mathrm{SQ}$ : number of boxes occupied by chipmunk or squirrel

NOFL: number of boxes occupied by a Northern Flicker

OTHER: number of boxes occupied by other inhabitants (see Appendix 1)

NO: number of unoccupied boxes 
TABLE 5. Eastern Screech-Owl prey inventory based on pellets and prey remains found in nest boxes at 6 orchards and 2 control sites in Saint-Hilaire and Rougemont areas, Quebec $(2001-2004)$

\begin{tabular}{|c|c|c|c|c|c|c|}
\hline Scientific name & Common name & $\mathrm{D} \backslash \mathrm{F}^{\mathrm{a}}$ & $\mathrm{B} \backslash \mathrm{K}$ & $\mathrm{N} \backslash \mathrm{N} 1$ & $\begin{array}{c}\text { Biosphere } \\
\text { Reserve }\end{array}$ & Campground \\
\hline Blarina brevicauda & Short-tailed Shrew & & 2 & 3 & 3 & 5 \\
\hline Microtus pennsylvanicus & Meadow Vole & 8 & 5 & 31 & 53 & 19 \\
\hline Peromyscus sp. & & & & 1 & & 5 \\
\hline Sorex sp. ${ }^{\mathrm{c}}$ & & 5 & & & 1 & \\
\hline Zapodidae $^{\mathrm{d}}$ & & 1 & & 3 & 13 & 1 \\
\hline Aegolius acadicus & Northern Saw-whet Owl & & & & 1 & \\
\hline Bombycilla cedrorum & Cedar Waxwing & & & & & 2 \\
\hline Cardinalis cardinalis & Northern Cardinal & & & & 1 & \\
\hline Carduellis tristis & American Goldfinch & & & & & 1 \\
\hline Colaptes auratus & Northern Flicker & & & & & \\
\hline Columba livia & Rock Dove & & & & & 3 \\
\hline Cyanocitta cristata & Blue Jay & 1 & & & 1 & 1 \\
\hline Junco hyemalis & Dark-eyed Junco & & & & & 1 \\
\hline Molothrus ater & Brown-headed Cowbird & 1 & & & & \\
\hline Poecile atricapillus & Black-capped Chickadee & 1 & & & & \\
\hline Picoides villosus & Hairy Woodpecker & & 1 & & & 1 \\
\hline Quiscalus quiscula & Common Grackle & & & & & 1 \\
\hline Sayornis phoebe & Eastern Phoebe & 1 & & & & \\
\hline Sturnus vulgaris & European Starling & & & & 1 & \\
\hline Toxostoma rufum & Brown Thrasher & 1 & & & & \\
\hline Turdus migratorius & American Robin & & 1 & & & 1 \\
\hline Zenaida macroura & Mourning Dove & 4 & 1 & & 1 & 8 \\
\hline Sittae & unidentified nuthatch & & & & 1 & \\
\hline Turdidae & unidentified thrush & 2 & & 1 & 1 & \\
\hline Tyrannidae & unidentified flycatcher & & 1 & 5 & & 12 \\
\hline \multicolumn{7}{|c|}{ Unidentified birde } \\
\hline \multicolumn{7}{|c|}{ Miscellaneous artifacts and prey } \\
\hline Apis mellifera & Honey Bee & 2 & & 2 & & 2 \\
\hline Rana clamitans & Green Frog & 1 & & & & 3 \\
\hline Unidentified membrane $^{f}$ & & 2 & & & 1 & 2 \\
\hline Corn, seeds & & 1 & & 1 & & 1 \\
\hline Eggshell fragments & & & & & 1 & 2 \\
\hline
\end{tabular}

a data spans 2001-2003 only

${ }^{\mathrm{b}}$ White-footed or Deer Mouse

${ }^{\mathrm{c}}$ Masked or Smoky Shrew

${ }^{\mathrm{d}}$ Meadow or Woodland Jumping Mouse

${ }^{\mathrm{e}}$ down remains unidentifiable

${ }^{\mathrm{f}}$ may be the remains of a frog

TABLE 6. Eastern Screech-Owls $(n=9)$ captured and banded in one control and six orchard locations of Saint-Hilaire and Rougemont areas Quebec (2001-2002), by month of capture. See methods for keel index categories.

\begin{tabular}{|c|c|c|c|c|c|}
\hline Location & $\begin{array}{l}\text { Capture } \\
\text { date }\end{array}$ & $\begin{array}{l}\text { Captured } \\
\text { individual }\end{array}$ & Weight (g) & $\begin{array}{l}\text { Keel index } \\
(0-5)\end{array}$ & $\begin{array}{l}\text { Wing chord } \\
(\mathrm{mm})\end{array}$ \\
\hline Orchard I & 22 July 2001 & 1 adult $^{\mathrm{a}}$ & 183 & 2.5 to 3.0 & 170 \\
\hline \multirow[t]{2}{*}{ Campground Control } & 13 July 2002 & 1 adult & 78.0 & 3 & 177 \\
\hline & & 3 juvenile & $78.0,94.0,96.0$ & $2,3,3$ & $182,184,194$ \\
\hline Orchard $\mathrm{K}^{\mathrm{b}}$ & 31 July 2002 & 1 adult & 160 & 3 & 176 \\
\hline \multirow{2}{*}{ Orchard A/A $1^{\mathrm{c}, \mathrm{d}}$} & 9 August 2002 & 1 adult & 159 & 4 & 176 \\
\hline & & 1 juvenile & 155 & 3 & 185 \\
\hline Orchard $\mathrm{D} / \mathrm{F}^{\mathrm{c}, \mathrm{e}}$ & 29 August 2002 & 1 juvenile & 171 & 4 & 178 \\
\hline
\end{tabular}

a red-phased individual

b 1 adult and 1 juvenile observed but not captured at B in June 2002

${ }^{c}$ orchards are adjacent to one another and considered to comprise one territory

d 1 other juvenile observed but not captured

e 1 adult and 2 juveniles observed in June 2001 but not captured 


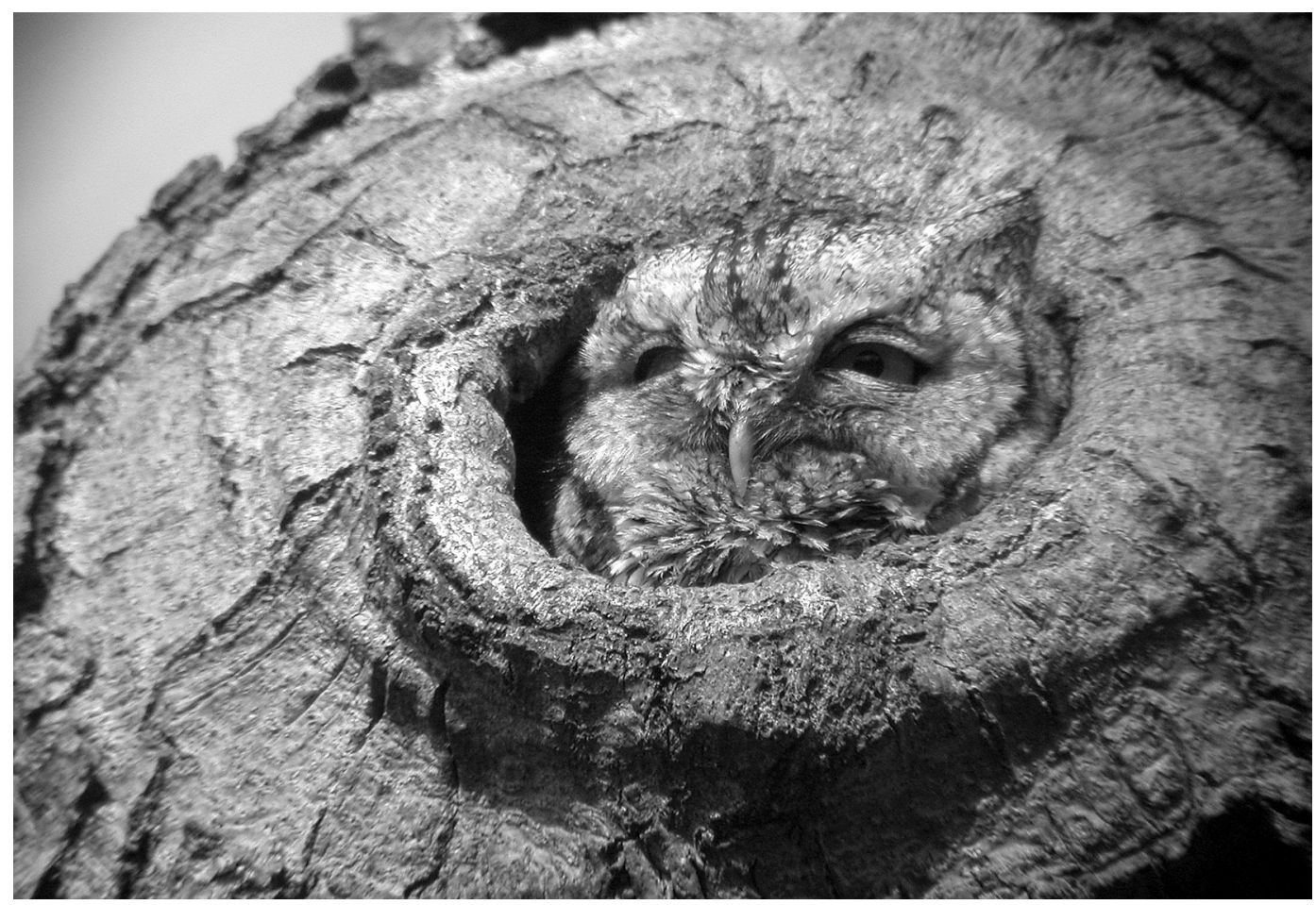

FIGURE 3. An Eastern Screech-Owl peers sleepily from a cavity at Parc Summit on the Island of Montreal. As development within the province increases, so too does the importance of the parks and protected areas within the species range. Photo by Jean-Sébastien Guénette, 17 April 2005.

given the necessity of devoting their energy to provisioning their mate and themselves, and to defending their territory against real rather than perceived intruders, censusing at this time can impose an unnecessary and potentially harmful stress. Predators of the ScreechOwl can also be attracted to the broadcast calls, and to respondents, especially if illuminated by a flashlight or headlamp. We are aware of one instance, for example, where a Long-eared Owl, Asio otus, was drawn to a Screech-Owl during censusing and was illuminated in the process of closing in on it. Since this study, a "minimal-disturbance" censusing protocol has been developed for the Screech-Owl and for other owl species (see Balej 2006).

\section{Nest Box inspections}

Nest boxes $(n=89)$ were installed in the vicinity of where Screech-Owls responded during censusing. Ordinarily, an owl's presence in an area would go largely undetected because they are very inconspicuous and occupy natural cavities. As the study progressed, our primary concern became to place the nest boxes at a height that would reduce the possibility of drawing untoward human attention to them. Overall nest box occupation at each location varied from $0 \%$ to $100 \%$. Forty-one boxes were occupied at least once by an owl, and these boxes were a mean of $3.8 \mathrm{~m}(2.0$ to
$5.8 \mathrm{~m}$ ) from the ground (Table 2). Gehlbach (1994b) found owls nesting, on average, $3.7 \mathrm{~m}$ from the ground in natural cavities $(n=23)$.

A number of species may compete with ScreechOwls for nest boxes. The four most frequent occupants were squirrels, Sciurus and Tamiasciurius sp., and chipmunks, Tamias striatus, Northern Flickers, Colaptes auratus, and Hymenoptera, especially wasps. During pre-snowfall inspections in October and November, we frequently removed nesting material left by other species, and during inspections the following spring found Screech-Owl pellets and prey remains. Occasionally, Screech-Owls deposed chipmunks and squirrels, judging from pellets or prey remnants deposited over nesting material. Northern Flickers have been reported to destroy Screech-Owl eggs (Penak 1986*). However, the Screech-Owls in our region infrequently (22 of the 146 recorded times) occupied nest boxes in the summer and early autumn months, when Flickers occupied them. Late autumn inspections enabled us to remove nesting material left by other species (or by Screech-Owls during the winter). We also could replenish the boxes with wood chips during these visits without having to disturb any of the species that had previously occupied the boxes and make any necessary repairs. 


\section{Pellets}

The intact pellets retrieved from nest boxes $(n=82)$ ranged widely in length from 1.0 to $8.5 \mathrm{~cm}$ and from 0.8 to $3.2 \mathrm{~cm}$ in width, with a mean weight of $1.77 \mathrm{~g}$. Elbroch and Marks (2001) recovered Screech-Owl pellets $(n=18)$ from nearby Vermont and New Hampshire which ranged from 1.6 to $3.8 \mathrm{~cm}$ length and 0.9 to $1.4 \mathrm{~cm}$ width. Fifty-six of our pellets exceeded the upper length and width reported by Elbroch and Marks. Most of the intact pellets we measured were retrieved from nest boxes, where they were protected from the elements and from breaking. This, and our larger sample size, may explain the discrepancy in our upper reported length.

\section{Prey Consumption}

Meadow voles were the predominant intact prey item found in our nest boxes. Screech-Owls are also highly insectivorous (Ritchison and Cavanagh 1992), and although we repeatedly found evidence of insect consumption, we were unable to fully assess or quantify it. Only insects with hard parts, such as beetles, Coleoptera, can be distinguished in pellets. For the most part, we found only a dust of legs and carapaces intermingled with the wood chips and with other artifacts. Mourning Doves were the avian prey most frequently found in nest boxes, but few avian prey remains were found. Screech-Owls may simply prefer to pluck feathers on a perch or in a deeper tree cavity rather than in a nest box which feathers could potentially fill quite quickly. Hence, our prey inventory underestimates avian and insect consumption. As well, several cached frogs and shrews, and a decapitated vole, were also found in nest boxes at the Campground control site. On a number of occasions, remnants of crayfish and fish scales were recovered from this site, as well as pieces of a greenish membrane, which may have been a remnant from the frogs. The greatest diversity in prey items seems to have been consumed at the Biosphere Reserve.

\section{Conclusion}

The Screech-Owl is found in suburban, rural and agricultural habitats. It is considered to be one of the most ubiquitous owls in North America (Gehlbach 1995). There is, however, very little information available about the species' natural history and ecology, or about its density and overall distribution in Canada, where its status was last evaluated for the Committee on the Status of Endangered Wildlife in Canada over 20 years ago (by Penak 1986*). Paradoxically, the species is currently designated as "Not at Risk", even though there are no current data on its population trend status (http://www.cws-scf.ec.gc.ca/mgbc/trends/ index.cfm?lang=e\&go=info $\cdot$ bird\&speciesid=3730).

An important part of the species' range in Canada occurs in southern Quebec, where it coincides with an agricultural belt and with the province's major appleproducing region. Screech-Owls are known to favour orchard habitats (Gauthier and Aubry 1996) where pesticides are intensively applied. Our study evaluating the exposure of Screech-Owls to pesticides currently and previously used in one of the largest apple-producing regions of southern Quebec provided an opportunity to collect information on the species' regional diet, record physiological parameters, evaluate occupation response to nest boxes and gain a sense of the density and distribution of the local population. As far as we know this is the first time that these types of data have been collected on the Screech-Owls of the area.

More baseline information of this type must be gathered for future monitoring and population management efforts throughout the owl's Canadian range. Changes in development and land use patterns must also be examined. While we found that exposure to DDE and organophosphorus pesticides warranted further investigation (see Richards et al. 2004, 2005), we also observed a marked increase in clearing and development of forested lands and orchards over the course of the study. We believe that loss of habitat and overall decrease in habitat quality currently pose a far greater threat to the local population than exposure to pesticides.

Our colleagues at the Quebec environment ministry (Ministère du Développement durable, de l'Environnement et des Parcs) have been conducting autumn and winter censuses in ecological reserves within the known range of the species since 2005. This is part of an ongoing study initiated to evaluate the relative risks that pesticide exposure and habitat loss/deterioration pose to Screech-Owls in southern Quebec (if interested in collaborating on this study, please contact $\mathrm{N}$. Richards).

Even if the North American Screech-Owl population may not be at risk as a whole, we are concerned that habitat loss and modification may be adversely affecting regional populations. At the very least, a reexamination of the Screech-Owl's distribution and population status throughout its Canadian range, especially in Quebec and Ontario, is long overdue. If this adaptable and opportunistic species is being adversely affected, how does this bode for the more vulnerable species which occupy the same habitats?

\section{Acknowledgments}

We are grateful to the orchard owners of the study area, without whose collaboration this study could not have taken place. We thank Terry Ryan and Jean Gougeon for building industrial quantities of nest boxes. Doctors Guy Fitzgerald and Claude Lacasse of the Clinique des oiseaux de proie and Annemarie Roth of the Centre for the Rehabilitation of Injured Birds of the Montérégie provided us with Screech-Owl admission records. Stéphane Deshaies and Annemarie Roth helped identify avian prey remains. Ambroise Lycke, Christine Bourque, Patrick MacFarlane, Anke Roth, Gavin McMorrow, Jessus Karst, Hugo Gee, Mar- 
cel Gahbauer, Tina Newbury, Amy Stevenson, Marisha Futer, Jean-Sébastien Guénette, Joanna Coleman and Anneli Jokela all provided invaluable assistance and/or training in the field. We thank Nicole Kopysh at the Ontario Bird Banding Atlas project and Becky Whittam at the New Brunswick division of Bird Studies Canada for information related to the ScreechOwl's distribution in these provinces. Caroline Cormier of Nature-Action, Québec Inc. and Gina Rossini provided information on the whereabouts of birds of prey in Rougemont and Saint-Hilaire. We are pleased to acknowledge the collaboration and hard work of Rodolph Balej and Marcelle Ruest at the Ministère de Development durable de l'Environnement et des parcs. Funding for this study was provided to N. L. Richards by the Fonds Québécois de la recherche sur la nature et les technologies and by the Canadian Wildlife Service, Environment Canada. Additional funding was provided through a Natural Sciences and Engineering Research Council of Canada (NSERC) grant to P. Mineau. Initial stages of the project were funded by Environment Canada's Science Horizons for Youth programme, in collaboration with World Wildlife Fund Canada. In particular, we gratefully acknowledge the continued funding and support provided by Bird Protection Quebec (BPQ) (formerly the Province of Quebec Society for the Protection of Birds - PQSPB).

Documents Cited (marked $*$ in text)

Penak, B. L. 1986. COSEWIC Status report on the Eastern Screech-Owl Otus asio in Canada. Ottawa, Ontario.

\section{Literature Cited}

Balej, R. 2006. Census of nocturnal raptors in the ecological reserves of the province of Quebec. Winter 2006-2007. Service des aires protégées, Direction du patrimoine écologique et des parcs, Ministère du Développement durable, de l'Environnement et des Parcs. 15 pages.

Cahn, A. R., and J. T. Kemp. 1930. On the food of certain owls in east-central Illinois. Auk 47: 323-328.

Elbroch, M., and E. Marks. 2001. Bird Tracks and Sign. Stackpole Books, Mechanicsburg, Pennsylvania.

Fuller, M. R., and J. A. Mosher. 1981. Methods of detecting and counting raptors: a review. Pages 235-246 in Estimating the numbers of terrestrial birds. Edited by C. J. Ralph and J. M. Scott. Studies in Avian Biology 6.
Gauthier, J., and Y. Aubry. 1996. Atlas of the breeding birds of southern Quebec. L'Association québécoise des groupes ornithologues, Province of Quebec Society for the Protection of Birds, the Canadian Wildlife Service, Quebec region, Montreal.

Gehlbach, F. R. 1994a. The Eastern Screech-Owl: life history, ecology, and behaviour in the suburbs and countryside. Texas A\&M University Press, College Station, Texas.

Gehlbach, F. R. 1994b. Nest-box versus natural-cavity nests of the Eastern Screech-Owl: an exploratory study. Journal of Raptor Research 28: 154-157.

Gehlbach, F. R. 1995. Eastern Screech-Owl, Otus asio. Pages 1-24 in The birds of North America (165). Edited by A. Poole and F. Gill. The Academy of Natural Sciences, Philadelphia, and The American Ornithologists' Union, Washington, D.C.

Henderson, C. 1992. Woodworking for wildlife: Homes for birds and mammals. Minnesota Department of Natural Resources.

Maisonneuve, C., R. McNicoll, S. St-Onge, and A. Desrosiers. 1997. Clé d'identification des micromammifères du Québec. Ministère de l'Environnement et de la Faune. Québec, Canada.

Raczynski, J., and A. L. Ruprecht. 1974. The effect of digestion on the osteological composition of owl pellets. Acta Ornithologica 84: 25-36.

Richards, N. L., P. Mineau, and D. M. Bird. 2004. Exposure of the Eastern Screech-Owl to organophosphorus insecticides and anticoagulant rodenticides in apple orchards of southern Québec, Canada. Pages 389-408 in Raptors Worldwide. Edited by R. C. Chancellor and B.-U. Meyburg. Proceedings of the Sixth World Conference on Birds of Prey and Owls. May 18-23, Budapest, Hungary.

Richards, N. L., P. Mineau, and D. M. Bird. 2005. A risk assessment approach to DDE exposure based on the case of the Eastern Screech-Owl (Megascops asio) in apple orchards of southern Québec, Canada. Archives of Environmental Contamination and Toxicology 49: 403-409.

Ritchison, G., and P. Cavanagh. 1992. Prey use by Eastern Screech-Owls: seasonal variation in central Kentucky and a review of previous studies. Journal of Raptor Research 26: 66-73.

VanCamp, L. F., and C. J. Henny. 1975. The Eastern Screech-Owl: its life history and population ecology in northern Ohio. North American Fauna 71: 1-65.

Received 26 July 2005

Accepted 4 June 2007 